\title{
REGISTROS DE REPRESENTAÇÃO SEMIÓTICA E GEOMETRIA DINÂMICA PARA O ENSINO DE CONGRUÊNCIAS DE FIGURAS GEOMÉTRICAS PLANAS
}

José Carlos Pinto Leivas leivasic@unifra.br 0000-0001-6876-1461 Centro Universitário Franciscano de Santa Maria, Santa Maria, Rio Grande do Sul- Brasil

Letícia dos Santos Fogaça lefogaca.sm@gmail.com 0000-0001-8631-1456 Centro Universitário FranciscanoUNIFRA- Brasil

\section{RESUMO}

Este artigo é um recorte de uma dissertação realizada pela primeira autora, orientada pelo segundo. Teve como objetivo analisar como alunos de uma turma de Geometria I, de um curso de Licenciatura em Matemática, constroem o conceito de congruência de figuras geométricas planas, por meio de registros de representação semiótica e geometria dinâmica. A metodologia foi a qualitativa, na forma de um estudo de caso, em que os métodos de coleta de dados forneceram a análise das produções dos estudantes. Foram elaboradas quatro unidades didáticas que conduziram à construção do conceito de congruência e dos casos clássicos de congruência de triângulos através de diferentes registros de representação. Os resultados mostraram que os estudantes conseguiram transitar dentro de um único registro e que as atividades oportunizaram a construção e compreensão desse conceito por meio dos registros de representação semiótica e do uso do software GeoGebra.
\end{abstract}

PALAVRAS-CHAVE: congruência de figuras geométricas planas, registros de representação semiótica, geometria dinâmica, unidades didáticas. 


\section{INTRODUÇÃO}

Apresenta-se, neste artigo, um recorte de uma dissertação de mestrado, o qual está estruturado da seguinte forma: na primeira parte, apresentam-se algumas considerações sobre a teoria dos registros de representação semiótica, mídias digitais aplicadas ao ensino, transformações geométricas e congruência de figuras para, numa segunda etapa indicar o objetivo e o locus da pesquisa com o caminho metodológico realizado. A seguir, realiza-se a análise dos dados ilustrada com as construções de um estudante em específico e, finalmente, as considerações finais.

\section{Registros de representação semiótica}

Iniciando-se o estudo concernente à teoria proposta por Raymond Duval, na busca de um melhor entendimento acerca de seu significado, verificou-se que a expressão "representações semióticas" denota o estudo de todas as linguagens existentes ou, ainda, a utilização de signos para representar objetos. Desse modo, a pesquisa está intrinsecamente ligada ao estudo apresentado por Duval, o qual aborda a utilização de diferentes representações semióticas para que o sujeito possa apropriar-se do conceito de um determinado objeto matemático. Em relação ao estudo das representações semióticas, Flores (2006, p. 79) destaca que "o interesse de Duval está, principalmente, no funcionamento cognitivo do aluno". Para ela, o pensamento é ligado às operações semióticas e, consequentemente, não haverá compreensão possível sem recorrer às representações semióticas.

Considerando-se o processo cognitivo dos indivíduos, é indispensável pesquisar como ocorre a comunicação e a aprendizagem, pois seu desenrolar é intrínseco à necessidade de adaptação e evolução da capacidade intelectual. Verifica-se, no Projeto Araribá (2010), a alusão a essa afirmação, pois se evidencia que a criação de signos como desenhos, sons, gestos, cores, letras e números, fez-se essencial para que se pudesse aprimorar a interlocução. E, nesse contexto, a linguagem proporciona o sentido a tudo que rodeia os seres humanos.

Duval (2006, p.106, tradução nossa), ressalta a importância dos registros de representação semiótica na evolução da compreensão matemática, afirmando que basta "observar a história do desenvolvimento da Matemática para ver que o desenvolvimento das representações semióticas foi uma condição essencial para o desenvolvimento do pensamento matemático".

Consequentemente, pode-se concluir que toda comunicação em Matemática é feita, basicamente, por meio de representações. Para ensinar conceitos, propriedades, estruturas e relações que derivam dos objetos matemáticos, o professor precisa apresentar aos seus alunos as diferentes formas de representação desses objetos, pois Duval (2014) assegura que não existe conhecimento que possa ser mobilizado por um indivíduo sem uma atividade de representação.

Ainda, conforme Duval (2003, p. 14), "a originalidade da atividade matemática está na mobilização simultânea de, ao menos, dois registros de representação, ou na possibilidade de trocar, a todo momento, o registro de 
representação". Para o autor, "é a articulação entre os registros que constitui uma condição de acesso à compreensão em matemática" (p. 22).

O autor defende que um registro de representação pode ser considerado semiótico quando permitir a formação de uma representação identificável. Esse registro será caracterizado pela utilização de dois tipos diferentes de transformação de representações semióticas, os tratamentos e as conversões e é, nesse momento, que o indivíduo é avaliado quanto ao seu efetivo entendimento matemático relativo ao objeto de estudo.

Os tratamentos constituem-se de transformações situadas dentro de um mesmo registro. Duval (2003) ressalta que, por vezes, o professor escolhe um único registro de representação e o elege como predominante, com o intuito de facilitar a compreensão dos seus alunos acerca do objeto de estudo, mas ratifica que essa atitude não facilita a aprendizagem dos discentes, além de limitar sua capacidade de compreensão e enclausurar o objeto de estudo dentro de um único registro. Complementando-se, as conversões são tratamentos que exigem a mudança de registro e esse tipo de transformação enfrenta os fenômenos de não congruência. Segundo Duval (2003), isso se traduz pelo fato de os alunos, muitas vezes, não reconhecerem o mesmo objeto por meio de duas ou mais representações diferentes.

Assim, pode-se verificar que a apreensão e o entendimento de um objeto matemático dependem do reconhecimento do estudante em diferentes registros de representação semiótica. Quando não há o reconhecimento do objeto matemático em outros contextos, pode-se supor que a causa seja a falta de associação entre esses registros de representação semiótica. Revela-se, portanto, a necessidade de proporcionar aos estudantes uma ampla percepção da variedade de representações utilizadas para denotar um mesmo objeto, bem como possibilitar a diferenciação entre o objeto e sua representação, pois isso torna as aulas mais dinâmicas e os novos conceitos podem tornar-se mais compreensíveis. Comungando-se com as ideias de Duval (2003), sob a perspectiva da teoria das representações semióticas, destaca-se a importância de proporcionar momentos de aprendizagem, por meio de registros distintos e da articulação entre todos eles.

\section{Mídias Digitais}

Uma das inúmeras opções de abordagem que o professor pode oportunizar a seus alunos é a utilização de mídias digitais. Esse recurso destaca-se frente às turmas, dada a forte tendência de utilização de computadores pela "geração digital", assim denominada por Schlemmer (2009). A educadora afirma que essa nova geração sente-se imersa em um mundo digital e em uma escola digital, ressaltando sua facilidade em manipular as tecnologias que estão ao seu redor.

Desse modo, a curiosidade dos jovens pelo mundo das tecnologias pode tornar-se uma aliada do professor, nas aulas de Matemática, por meio da utilização de celulares, tablets e computadores (tanto em sala de aula, quanto em laboratórios de informática), uma vez que pode desencadear maior interesse e participação, podendo gerar, por conseguinte, uma aprendizagem com produção de significado. 
A importância das instituições de ensino utilizar as tecnologias digitais como elementos de apoio, durante as aulas de Matemática, também é evidenciada nos Parâmetros Curriculares Nacionais (BRASIL, 2005), nos quais se verifica que,

o computador é apontado como um instrumento que traz versáteis possibilidades ao processo de ensino e aprendizagem de matemática, seja pela sua destacada presença na sociedade moderna, seja pelas possibilidades de sua aplicação nesse processo. Tudo indica que seu caráter lógico-matemático pode ser um grande aliado do desenvolvimento cognitivo dos alunos, principalmente na medida em que ele permite um trabalho que obedece a distintos ritmos de aprendizagem (p. 47).

Diante de tais constatações, revela-se a necessidade da inserção de aulas que utilizem o laboratório de informática, principalmente, nos cursos de licenciatura, pois, desse modo, o futuro professor vivencia a importância de possibilitar aos futuros alunos uma maneira diversificada e dinâmica de compreensão dos conceitos estudados.

De fato, Borba e Penteado (2003) destacam que professores de Matemática em formação precisam receber, durante a trajetória acadêmica, atividades que envolvam a utilização competente das tecnologias de informação, pois eles deverão estar capacitados para atender às demandas escolares logo à frente. Além disso, na formação acadêmica do futuro professor, a instrumentalização, por meio da plataforma computacional, é crucial para contemplar a construção do seu conhecimento.

Salienta-se que promover atividades que envolvam a utilização do laboratório de informática, além de proporcionar o dinamismo do trabalho em equipe, pode provocar uma mudança de postura, na qual o professor pode tornar-se um elemento importante do processo, atuando como mediador do trabalho dos alunos, interferindo sempre que necessário, mas instigando suas reflexões e ações.

Diante do computador, os discentes passam a realizar atividades com mais dinamicidade, que diferem da configuração, por vezes, estática da sala de aula, na qual o professor explicita os conceitos no quadro e o aluno somente os reproduz no caderno. Quando o docente planeja atividades que promovem a modificação do cenário da aprendizagem, delineando aulas que proporcionem maior interação e significação, pode estar propiciando aulas mais interessantes e atraentes aos seus educandos.

Assim, estando envolvidos em uma atividade que aborde um determinado conteúdo matemático, por meio da utilização do computador, além de ampliar a capacidade de experimentação, os alunos têm a oportunidade de aprender a utilizar um software matemático com ferramentas interativas, alcançando o objetivo proposto pelos Parâmetros Curriculares Nacionais (BRASIL, 1998).

\section{Transformações geométricas}

Uma transformação geométrica é uma aplicação bijetiva entre duas figuras geométricas, no mesmo plano ${ }^{1}$ ou em planos diferentes, de modo que, a partir de

\footnotetext{
Păgina ${ }^{84}{ }^{1}$ As transformações geométricas também podem relacionar figuras geométricas no mesmo espaço ou em espaços
} diferentes. 
uma figura geométrica inicial, forma-se outra congruente à primeira. As transformações geométricas podem ser de reflexão, translação ou rotação e permitem que uma figura inicial corresponda a uma figura final, de modo que seu tamanho, forma e distância entre dois pontos homólogos ${ }^{2}$ quaisquer dessas duas figuras sejam preservados. Portanto, diz-se que duas figuras geométricas são congruentes se, e somente se, estão relacionadas por meio de qualquer uma das transformações geométricas, denominadas movimentos rígidos ou isometrias, justamente pela rigidez com que preservam suas características.

Cabe ressaltar os diferentes campos operacionais das transformações geométricas, pois elas diferem quanto à sua natureza. Nesta pesquisa, são evidenciadas as transformações no plano, desse modo, as translações e as rotação são movimentos no campo operacional 2D e as reflexões são movimentos no campo operacional 3D, pois é necessário retirar a figura do plano para executar tal movimento. Além disso, é importante denotar as dimensões das unidades figurais. Dessa forma, os pontos situam-se no campo operacional OD, as retas e as curvas (de mesmo modo, os vetores, as semirretas e os segmentos) denotam-se no campo operacional 1D, as figuras poligonais e os círculos encontram-se no campo operacional 2D e os prismas, pirâmides e as esferas (figuras espaciais) constituem-se no campo operacional 3D.

\section{Congruências de figuras geométricas planas}

Verifica-se que os materiais de apoio ao professor para o estudo de congruência de figuras geométricas planas preconizam, de maneira geral, a congruência de triângulos. Além disso, nesses materiais, a abordagem apresentada é axiomática, o que se pode verificar em Bianchini (2011), Dante (2005), Giovanni, Castrucci, Giovanni Jr. (2011) e no Projeto Araribá (2007), coleções destinadas ao ensino fundamental e, ainda, em Barbosa (2006) e Rezende e Queiroz (2000), que são literaturas com ênfase no ensino superior.

Supondo que o professor tenha, como único guia, um livro didático e que faça esse tipo de tratamento, provavelmente a construção do conceito de congruências de seus alunos ocorrerá de maneira teórica, por meio de definições dos casos clássicos de congruência de triângulos, sem que eles tenham a oportunidade de experienciar e construir o próprio conceito, para compreender cada um desses casos. Caso opte por delinear suas aulas dessa maneira, o professor preconiza um processo de transmissão de informação, apresentando as demonstrações como algo irrefutável e supostamente eficiente, não dando chance ao legítimo ato do pensar matematicamente do aluno acontecer, conforme evidenciado em Almoloud (2000).

Verifica-se a precariedade da abordagem de determinados conceitos geométricos, em alguns livros didáticos, nas palavras de Lorenzato (1995), o qual pontua que, neles, a Geometria é apresentada

apenas como um conjunto de definições, propriedades, nomes e fórmulas, desligado de quaisquer aplicações ou explicações de natureza histórica ou lógica; noutros, a geometria quase sempre é apresentada na última parte do

\footnotetext{
Păgina $\quad{ }^{85}$ Os pontos correspondentes são denominados pontos homólogos, ou seja, cada ponto de uma figura deve ter seu
} ponto homólogo na outra. 
Além disso, destaca-se a pouca variedade de literaturas que abordam o tema, por meio da utilização de tecnologia computacional ou de materiais manipuláveis, pois, em nenhuma das referências citadas anteriormente, verificaram-se essas opções como sugestão de atividade. Sinaliza-se, portanto, para a importância da utilização de livros didáticos como um instrumento de apoio e não como um guia a ser seguido fidedignamente. $O$ professor precisa incluir tantas abordagens quantas julgar necessárias em suas aulas, porque, caso siga determinado livro como único roteiro de suas aulas, poderá limitar substancialmente a sua prática e comprometer o processo de aprendizagem de seus alunos.

\section{Objetivo e descrição do locus}

O objetivo da pesquisa foi investigar como os alunos de uma turma de ensino superior, na disciplina de Geometria I, constroem o conceito de congruência de figuras geométricas planas, por meio de registros de representação semiótica e geometria dinâmica. Ressalta-se a relevância do estudo desse conceito básico da Geometria nos cursos de licenciatura, uma vez que, conforme apontado por Leivas (2009), o ensino de Geometria, na escola básica, limita-se ao uso de fórmulas, não privilegiando outras dimensões consideradas essenciais para o desenvolvimento do pensamento geométrico.

Outrossim, muitos materiais de apoio ao professor enfatizam, de maneira geral, a congruência de triângulos, deixando de lado a congruência dos demais tipos de figuras planas. Além disso, caso esse tratamento seja feito teoricamente, somente por meio de definições dos casos clássicos de congruência, isso poderá ser somente uma maneira de vencer o programa da disciplina, não preconizando a produção de significado dos estudantes, que logo serão professores incumbidos de ensinar tais conceitos aos seus alunos.

Para a execução das atividades desta pesquisa, foi escolhido o software GeoGebra, que se encontra disponível para download em: $<$ http://www.geogebra.org/cms/pt_BR/>. Trata-se de um software gratuito, que pode ser utilizado para o ensino e aprendizagem de Matemática dinâmica em todos os níveis de ensino. Seu potencial facilita a construção geométrica pretendida, aumenta a sua precisão e diminui o tempo gasto para realizá-la. Ajuda a enriquecer o processo de aprendizagem da Geometria, além de valorizar o conhecimento matemático.

Esta pesquisa foi realizada no Centro Universitário Franciscano, localizado na cidade de Santa Maria - RS, durante o primeiro semestre de 2015. Participaram desta, cinco estudantes ${ }^{3}$ do curso de licenciatura em Matemática, matriculados na disciplina de Geometria I, a qual é ofertada no quinto semestre do curso. A metodologia empregada foi de cunho qualitativo, na forma de um estudo de caso, em que os métodos de coleta de dados representaram a análise das produções verbais, escritas e computacionais produzidas pelos estudantes.

${ }^{3}$ A turma era composta somente por cinco estudantes e todos participaram desta pesquisa. 
Referindo-se à pesquisa qualitativa, Laperriére (2010) ressalta que ela tem um caráter interativo e leva à reflexividade da pesquisa, preconizando um conhecimento do contexto e da diversidade dos atores envolvidos nesse ambiente. Além disso, Lüdke e André (2013, p. 11) enfatizam que o método qualitativo "tem o ambiente natural como sua fonte direta de dados e o pesquisador como seu principal elemento; os dados coletados são predominantemente descritivos; a preocupação com o processo é muito maior do que com o produto $[\ldots]^{\prime \prime}$.

Durante a investigação, utilizou-se um gravador ${ }^{4}$ e um diário de campo, no qual foram anotadas as percepções e aspectos observados pela professora investigadora ${ }^{5}$ no desenrolar das atividades. As anotações foram feitas durante e, principalmente, ao final de cada encontro, para que não se perdesse nenhum dado importante na descrição dos itens estudados.

Por meio da sequência de atividades propostas, conduziram-se os estudantes à percepção das relações entre os diferentes registros de representação, para entender o conceito de congruência de figuras planas, utilizando as transformações geométricas. Realizaram-se enfoques distintos da abordagem do conceito de congruência de figuras geométricas planas e analisaram-se os registros de representação semiótica produzidos pelos estudantes ao longo das atividades das quatro unidades elaboradas. A turma em questão fez todas as atividades no laboratório de informática da instituição. $\mathrm{Na}$ primeira unidade, utilizaram materiais manipuláveis (tesoura e papel de seda); na segunda unidade, não contaram com o auxílio de nenhum material de apoio e, na terceira e quarta unidades, utilizaram o software GeoGebra.

\section{Caminho metodológico e análise dos dados}

As atividades foram aplicadas, em três encontros de dois períodos, com cinquenta minutos cada um. Cabe ressaltar que, neste recorte, será apresentado o detalhamento das atividades somente do estudante $1^{6}$. A primeira unidade teve como objetivo verificar como os alunos utilizaram os registros de representação semiótica, a fim de apurar a definição de congruência de duas figuras planas. Para que os estudantes conseguissem desenvolver plenamente as atividades propostas nessa unidade, seria necessário que efetuassem os dois tipos de transformações: tratamentos com registros manuais (dentro do registro figural) e conversões do registro figural para o discursivo (verbal e escrito). Além disso, seria preciso transitar entre operações 2D (rotações e translações) e 3D (reflexões).

Para dar início à tarefa, distribuiu-se uma folha com oito pares de figuras congruentes, juntamente com um pedaço de papel de seda. Nesse momento, a orientação dada foi a seguinte: "primeiramente. vocês identificarão pares de figuras semelhantes ${ }^{7}$. Então, utilizarão o papel de seda para sobrepor e contornar

${ }^{4}$ Solicitou-se autorização prévia dos estudantes para utilizar os seus registros verbais.

${ }^{5}$ Identifica-se a autora desta pesquisa como professora investigadora, por ter assumido a turma durante a aplicação das atividades. A docente que cedeu sua turma para o desenvolvimento das ações é denominada professora regente.

Página | $87^{6}$ Escolheu-se o estudante 1 por considerá-lo uma boa amostra do que ocorreu com os demais participantes.

7 Justifica-se o fato de ter utilizado a palavra semelhantes, porque os estudantes ainda tinham dúvida sobre o significado de congruência. 
uma das figuras (figura de partida), a fim de obter um molde. Após, deslocarão esse molde até a figura de chegada, com o intuito de sobrepô-la exatamente, verificando a coincidência do par. Por fim, precisarão descrever quais movimentos tiveram de realizar com o papel de seda para realizar essa sobreposição."

Abaixo se apresenta o par (1-14), contudo destaca-se que as figuras que o compõem não se apresentavam lado a lado, na folha entregue aos alunos, as quais estavam dispostas distantes e misturadas às demais figuras.

Figura 1 - Exemplificação do par (1-14) da unidade 1

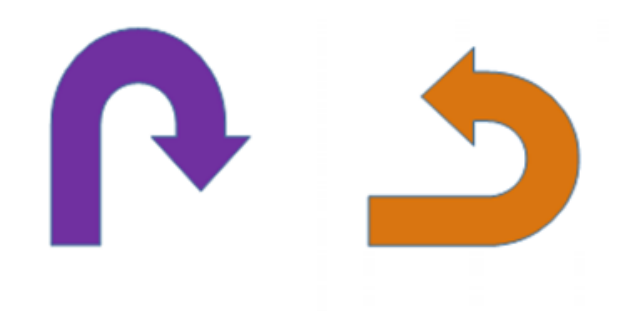

(Fonte: autor)

Nessa tarefa, houve uma heterogeneidade de palavras, mencionadas por todos os estudantes, na tentativa de explicar suas constatações. A título de exemplo, é possível verificar o registro escrito do estudante 1.

Figura 2 - Descrição do par (1-14) da unidade 1 pelo estudante 1

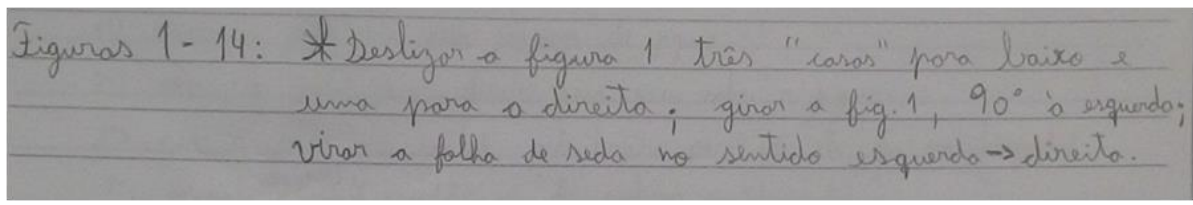

(Fonte: dados da pesquisa )

Observa-se que o estudante 1 teve a preocupação de explicitar, detalhadamente, as translações realizadas com o papel de seda, inclusive descreveu o ângulo de rotação feito, ainda que tenha utilizado a palavra girar e, por fim, descreveu o movimento de reflexão como "virar a folha". Notam-se, ainda, indícios de que o aluno percebeu um eixo de simetria, pois destacou que a figura 1 "virou" da esquerda para a direita, ou seja, refletiu em relação a um eixo de simetria vertical, para conseguir encaixar na figura 14. Entretanto, no par subsequente, o estudante expressou palavras idênticas para explicar movimentos diferentes e em campos operacionais distintos. Na figura 3, apresenta-se a ilustração do segundo par de figuras. 
Figura 3 - Exemplificação do par (12-15) da unidade 1
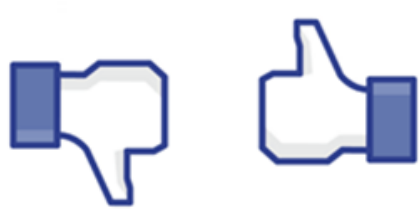

(Fonte: autor)

Evidenciou-se a dificuldade na verificação dos diferentes campos operacionais nos registros discursivos - verbal e escrito - de todos os estudantes. Para exemplificar, apresenta-se, na figura 4, o registro produzido pelo estudante 1.

Figura 4 - Descrição do par (12-15) da unidade 1 pelo estudante 1

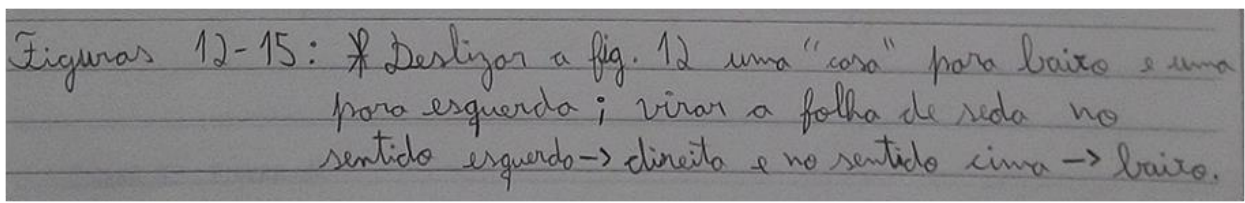

(Fonte: dados da pesquisa )

Nesse registro, verifica-se que, para explicar que realizou uma rotação no sentido horário, o estudante 1 dissertou que foi preciso "virar a folha no sentido esquerda-direita" mas, se for retomada sua descrição concernente ao par (1-14), verifica-se que ele havia descrito o movimento de reflexão como "virar a folha no sentido esquerda-direita". Portanto, suas descrições para os movimentos de reflexão - 3D e rotação $2 \mathrm{D}$ - foram exatamente iguais.

Diante das constatações, constatou-se que os estudantes demonstraram indícios da construção do conceito de congruência. A análise de suas formulações revelou, no entanto, várias incompreensões vinculadas às operações discursivas. Sobre esse tipo de verificação, Duval (2014, p. 21) afirma que "essas incompreensões merecem, entretanto, mais que especial atenção, uma vez que elas constituem a prática mais elementar da descrição geométrica de uma figura, isto é, da articulação entre enunciados de instrução de uma figura". Com base nas palavras de Duval (2003), pode-se concluir que o fenômeno de não congruência foi verificado nas atividades da unidade 1 , pois os estudantes não conseguiram transitar espontaneamente entre os diferentes registros.

As atividades das unidades 1 e 2 foram realizadas no mesmo dia. Nessa tarefa, o objetivo foi verificar como os estudantes relacionavam as simetrias por meio da visualização. Esperava-se que eles percebessem os movimentos realizados em cada figura, associando-os a uma transformação geométrica, e que descrevessem como os pares de figuras estavam relacionados sem a utilização do papel de seda. Para isso, a visualização teria um papel fundamental no processo. Distribuiu-se uma folha com pares de figuras congruentes, na qual os estudantes teriam de descrever como verificavam a congruência de cada par.

O estudante 1 demonstrou não diferenciar os movimentos de rotação e de translação, pois descreveu uma reflexão no eixo horizontal. Quando questionado 
sobre esse movimento, ele argumentou: "eu girei, digo, rotacionei para virar a figura de ponta-cabeça, deslocando para encostar na outra". Verifica-se que o estudante explicitou, verbalmente, o movimento de rotação para sobrepor a figura de chegada, entretanto descreveu, na folha, uma reflexão. Mesmo diante do questionamento da professora investigadora, ele não detectou a diferenciação entre seu registro verbal e seu registro escrito. A figura 5 contém a tarefa desse estudante.

Figura 5 - Descrição do primeiro par da unidade 2 pelo estudante 1

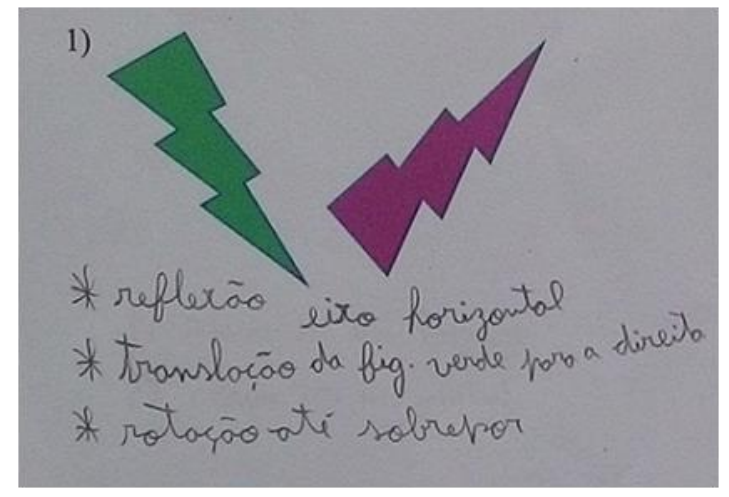

(Fonte: dados da pesquisa)

Complementando sua argumentação ele afirmou: "preciso refletir a figura no eixo horizontal, para girá-la para fora da folha e levar até o outro lado e esse movimento é uma rotação". O movimento de levar a figura para o outro lado, a que ele se referiu, está localizado no ambiente operacional 3D, entretanto ele defendeu que esse movimento era, ao mesmo tempo, uma reflexão e uma rotação. Portanto, ratifica-se a dificuldade do estudante na visualização e diferenciação das operações 2D e 3D. Configura-se que o estudante 1 apresentou um fenômeno de não congruência semântica, pois não conseguiu transitar espontaneamente do registro figural até o registro discursivo. Além disso, não realizou o tratamento necessário, pois não relacionou corretamente as figuras de partida e de chegada.

Desse modo, durante a realização das atividades da unidade 2 , foi notável a dificuldade dos estudantes na visualização das operações. Essa conclusão também é explicitada no estudo de Leivas (2009), quando ele aponta os resultados de um levantamento nos currículos de cursos de licenciatura de oito universidades do Estado do Rio Grande do Sul e assegura que não foi percebido qualquer indicativo de que a visualização seja um elemento norteador do ensino de Geometria em nenhuma das instituições.

Alerta-se para a importância da inserção de atividades que estimulem a visualização nos diferentes níveis de ensino, como se pode verificar em Marin (2013) e em Leivas (2012), pois esse tipo de exercício é essencial para a aprendizagem de conceitos geométricos, sobretudo de conceitos matemáticos que, muitas vezes, apresentam-se isentos de representação geométrica.

Nas atividades da unidade 3, o objetivo foi verificar como os estudantes continuaram construindo o conceito de congruência de figuras geométricas planas, utilizando o software GeoGebra para identificar as transformações geométricas envolvidas entre as posições das figuras. Foi preciso descrever cada 
troca de posição desde a primeira até a última. Disponibilizou-se, no software, uma figura inicial, juntamente com uma folha contendo trocas de posições dessa figura, para que os estudantes as reproduzissem na tela do computador.

Para efetuar os tratamentos, seria necessário transitar dentro do registro figural, utilizando as transformações geométricas necessárias, a fim de obter cada nova posição e, para realizar as conversões, seria preciso transitar do registro figural até os registros discursivos - verbal e escrito - para escrever e descrever cada movimento. Na figura 6, apresenta-se o primeiro modelo de figuras disponibilizado.

Figura 6 - Tela modelo da primeira atividade da unidade 3

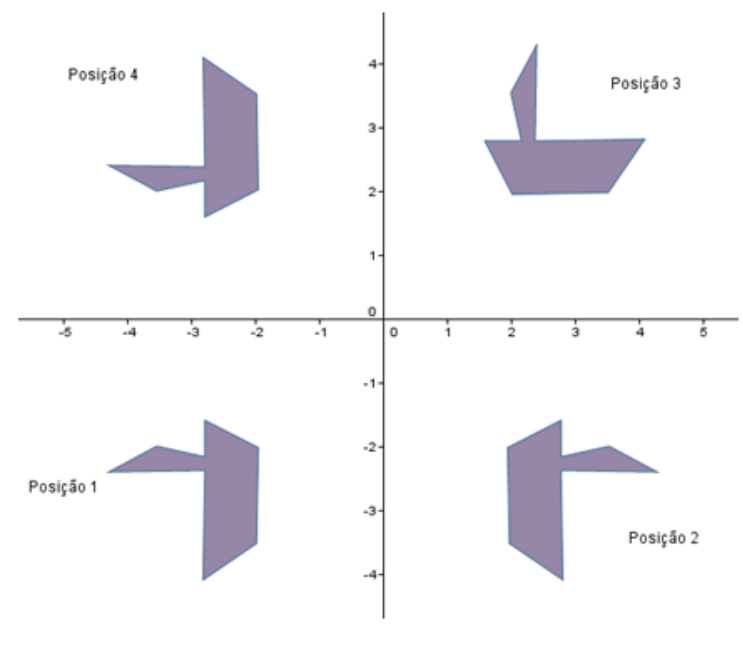

(Fonte: autor)

Ressalta-se que todos os estudantes reproduziram, corretamente, o registro figural disponibilizado nessa e nas demais atividades dessa unidade. Entretanto, houve variações nos procedimentos realizados para obter tais registros.

O estudante 1 optou por utilizar a ferramenta disponível no ambiente, a fim de apresentar seu registro discursivo e explicitou o que se apresenta na figura 7.

Figura 7 - Descrição da 1a atividade da unidade 3 pelo estudante 1

1 - 2) Refletir figura inicial em torno do eixo y
2 - 3) Rotacionar figura 2 em $270^{\circ}$ sentido horário em torno
do ponto de origem $(0,0)$
1 - 4) Refletir figura inicial em torno do eixo x

(Fonte: dados da pesquisa)

Quando questionado sobre suas ações, ele verbalizou: "Criei um ponto A sobre o eixo y para rotacionar a posição 3 até a posição 4, mas percebi que era só refletir a posição 1 sobre o eixo x que dava na mesma". Portanto, o discente demonstrou indícios da verificação de que uma reflexão pode ser obtida com a combinação de duas ou mais transformações. Ele realizou os tratamentos e as conversões com sucesso, pois seus diferentes registros estavam em consonância. Desse modo, o estudante 1 configurou um caso de congruência semântica. 
Sintetizando-se as análises dessa unidade, concluiu-se que o tratamento, dentro do registro figural, não ofereceu dificuldade para os estudantes. No entanto, a conversão do registro figural para os dois tipos de registro discursivo apresentou poucos acertos parciais (somente os estudantes 1 e 2 obtiveram êxito).

Assim, segundo Duval (2003), esses estudantes estariam em uma fase de transição na compreensão entre os diferentes registros de representação semiótica do objeto matemático congruência, pois acertaram algumas conversões, erraram outras e, às vezes, não conseguiram apresentar clareza em suas produções escritas.

Nas atividades da unidade 4, o objetivo era conduzir os estudantes à construção dos casos clássicos de congruência de triângulos. Para isso, eles realizaram atividades no software GeoGebra, porém não lhes foi apresentada qualquer leitura inicial sobre os casos de congruência de triângulos. Esperava-se que eles descobrissem e formalizassem esses conceitos por meio de suas conjecturas, de maneira não axiomática.

Na primeira tarefa, os estudantes foram levados a construir o caso clássico: lado, lado, lado (LLL), o qual pontua que dois triângulos com os três lados respectivamente congruentes são congruentes, conforme Giovanni, Castrucci e Giovanni Jr. (2011). Na sequência, apresenta-se a atividade.

Questão 1: Considere três segmentos $a=3 \mathrm{~cm}, b=4 \mathrm{~cm} \mathrm{e} c=5 \mathrm{~cm}$. Construa um triângulo de lados a, b e c. Quantos triângulos diferentes podem ser construídos com essas características a menos de posição?

Nessa situação, não importaria qual o segmento inicial construído, pois o triângulo obtido seria sempre o mesmo. Porém, seria necessário perceber que a figura poderia se apresentar rotacionada. Outra possibilidade seria que algum estudante considerasse o ponto de intersecção inferior. Ele construiria o mesmo triângulo, porém a figura estaria refletida em relação a um eixo de simetria. A figura 8 apresenta o registro figural e algébrico do estudante 1.

Figura $8-1$. $^{\text {a }}$ questão da unidade 4 , pelo estudante 1

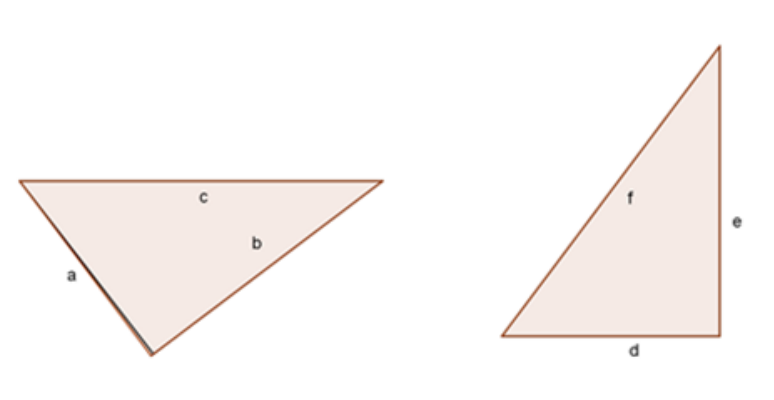

(Fonte: dados da pesquisa)

Como se pode verificar, o estudante 1 construiu dois triângulos. No primeiro deles, iniciou a construção pelo segmento de $5 \mathrm{~cm}$ e, no segundo, iniciou pelo segmento de $3 \mathrm{~cm}$. Questionou-se sobre o porquê de ele ter feito essas duas construções, obtendo-se como resposta: "São duas construções, mas é o mesmo triângulo, só que o primeiro não está de pé". 
A professora investigadora devolveu outra pergunta: "E como você faria para ele ficar em pé?". O estudante afirmou: "Eu rotacionaria ele". Quando se solicitou que ele explicasse com suas palavras como definiria o caso de congruência ele destacou: "Com três lados, só construo um triângulo".

Evidencia-se que o estudante conseguiu transitar espontaneamente entre os seus registros figurais e algébricos, entretanto, na conversão do registro figural para o discursivo, apresentou dificuldades referentes à linguagem, pois sua afirmação não fazia sentido para denotar o caso de congruência LLL. Enquanto contava com o suporte figural na tela do computador, conseguiu explicar suas conjecturas, porém, sem o auxílio visual, suas dificuldades foram notáveis. Desse modo, o estudante 1 realizou tratamentos, não efetuou conversões e delineou um caso de não congruência semântica.

Iniciando-se a segunda tarefa, os estudantes foram incentivados a construir o caso clássico: lado, ângulo, lado - LAL, o qual pontua que são congruentes dois triângulos que possuem dois lados e o ângulo compreendido por esses lados, respectivamente, congruentes, segundo Giovanni, Castrucci e Giovanni Jr. (2011). A seguir, apresenta-se o exercício proposto.

Questão 2: a) Considere dois segmentos $\mathrm{a}=5 \mathrm{~cm}$ e $\mathrm{b}=8 \mathrm{~cm}$ e um ângulo $\alpha=$ $35^{\circ}$, fixo, formado pelos dois segmentos. Construa um triângulo com essas informações. Quantos triângulos diferentes se podem construir com essas características a menos de posição? b) Se você não fixar o ângulo $\alpha$ formado pelos segmentos $a$ e $b$, o triângulo construído será congruente ao primeiro?

Nessa situação, os estudantes foram conduzidos a conjecturar que a ordem LAL é importante, pois no item (b) tiveram a oportunidade de verificar que, caso o ângulo não fosse fixo entre os dois segmentos, os triângulos construídos não seriam congruentes.

O estudante 1 construiu o triângulo de duas maneiras distintas, para certificar-se de suas ideias e afirmou à professora investigadora: "Por mais que eu mude a posição, sempre que eu fixar o ângulo entre os dois lados, vou construir o mesmo triângulo". Então, a professora o indagou sobre o tem b (não fixar o ângulo entre os segmentos), pois o aluno não apresentou seu registro figural. Na sequência, o estudante afirmou: "Eu fiz, mas não deu o mesmo triângulo, daí apaguei". A professora solicitou que o estudante o apresentasse novamente, pois, no software, é possível retomar construções anteriores sem ter que reconstruir o passo a passo. $O$ estudante afirmou que o faria, entretanto, na hora da análise, verificou-se que o item não foi apresentado, como se observa na figura 9. 
Figura $9-2 .^{\text {a }}$ questão da unidade 4 , pelo estudante 1

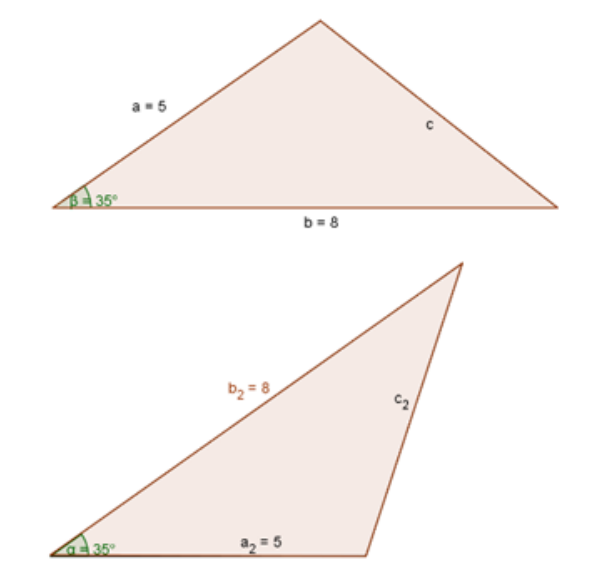

(Fonte: dados da pesquisa)

Referindo-se ao delineamento de sua atividade, o estudante 1 transitou entre os registros figural, algébrico e discursivo. Mesmo que não tenha apresentado o registro figural do item (b), conjecturou a importância da ordem, para que o caso de congruência fosse satisfeito, o que configurou um caso de congruência semântica.

Na terceira atividade, os estudantes construíram o caso clássico: ângulo, lado, ângulo - ALA. O teorema pontua que dados dois ângulos e um lado de um triângulo, ele será o único formado com essas três medidas, salvo a posição em que sejam representados.

Assim, a questão 3 apresentava dois itens:

a) Considere dois ângulos, um $\alpha=45^{\circ}$ e outro $\beta=30^{\circ}$, que possuam um lado comum $a=3,5 \mathrm{~cm}$ entre eles. Construa um triângulo com essas informações. Quantos triângulos diferentes podemos construir com essas características a menos de posição?

b) Se você não fixar o segmento "a" como lado comum aos ângulos $\alpha$ e $\beta$, o triângulo construído será congruente ao primeiro?

O estudante 1 apresentou seus registros figural e algébrico, conforme a figura 10. 
Figura $10-3 .^{a}$ questão da unidade 4 , pelo estudante 1

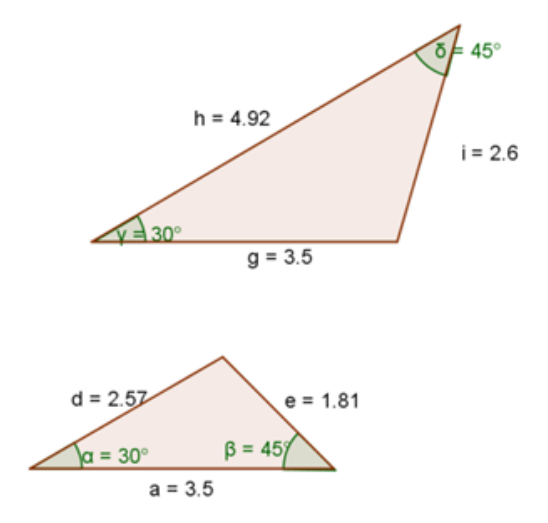

(Fonte: dados da pesquisa)

Constata-se que ele conseguiu transitar facilmente entre seus registros figural e algébrico, pois explicitou e relacionou, corretamente, os dois itens solicitados. Ele afirmou à professora investigadora: "Dá pra ver que eu tenho dois triângulos completamente diferentes, dependendo do lugar que eu fixo o segmento e os ângulos".

Quando questionado sobre como poderia descrever o caso de congruência, ele destacou: "Quando considerar dois ângulos unidos por um segmento, eu sempre vou ter triângulos congruentes". O estudante complementou sua afirmação destacando que: "Se eu tivesse construído primeiro o ângulo de $45^{\circ}$, do lado esquerdo e tivesse deixado o ângulo de $30^{\circ}$, do lado direito, teria o mesmo triângulo, mas refletido em relação a um eixo vertical". Verifica-se que, mesmo apresentando dificuldades na formalização do teorema, seus registros figural, algébrico e discursivo estavam em consonância, o que delineou um fenômeno de congruência semântica.

$\mathrm{Na}$ quarta atividade, os estudantes construíram o caso clássico de congruência: lado, ângulo, ângulo oposto - LA $A_{o}$, o qual pontua que, dado um ângulo adjacente à um segmento e um ângulo oposto ao mesmo segmento, haverá um único triângulo, salvo posição, formado com essas características, Giovanni, conforme Castrucci e Giovanni Jr. (2011). A seguir, pode-se verificar o exercício proposto.

Questão 4: Considere um segmento $a=4 \mathrm{~cm}$ e os ângulos $\alpha=45^{\circ}$ e $\beta=60^{\circ}$. Construa um triângulo de maneira que o ângulo $\alpha$ seja adjacente ao segmento "a" e o ângulo $\beta$ seja oposto ao segmento "a". Quantos triângulos diferentes podemos construir com essas características a menos de posição?

Nessa atividade, os estudantes compararam suas construções, na tela dos computadores, para verificar se os triângulos formados eram congruentes ou não, o que gerou grande envolvimento e discussão. Como essa atividade era a última, os alunos estavam ansiosos para conjecturar o teorema que faltava. Adianta-se que todos eles obtiveram êxito nos tratamentos e nas conversões exigidas nessa tarefa, de modo que o fenômeno de congruência semântica foi evidenciado em todas as atividades. 
O estudante 1 apresentou, corretamente, o registro figural e algébrico, como se pode verificar na figura 11 , pois realizou, corretamente, os tratamentos necessários dessa atividade.

Figura $11-4 .^{\text {a }}$ questão da unidade 4, pelo estudante 1

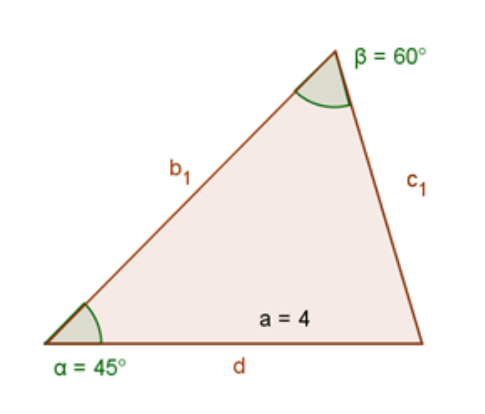

(Fonte: dados da pesquisa)

Além disso, ele transitou, facilmente, para o registro discursivo verbal, pois afirmou: "O triângulo é o único formado dessa maneira; a minha construção é igual à dos meus colegas. O triângulo só vai mudar de posição, mas será sempre congruente". Ele complementou como verificou o caso de congruência: "Com dois ângulos e um lado, mas na ordem lado, ângulo, ângulo oposto tenho sempre congruência de triângulos". Verificou-se que o estudante realizou os tratamentos e as conversões corretamente, o que delineou o fenômeno de congruência semântica.

\section{Considerações finais}

No decorrer de todas as unidades, destacou-se a predominância da utilização do registro discursivo escrito, em detrimento de todos os outros tipos de registro exigidos. Essa postura é evidenciada no estudo de Duval (2011), no qual o autor destaca que, para redigir um texto em língua natural,

\footnotetext{
o problema didático do domínio da língua não é o conhecimento do vocabulário, mas a capacidade de poder designar muitas coisas com as palavras de que se dispõe. $O$ conhecimento das palavras não é nada se não existe uma tomada de consciência das operações de designação e de suas complexidades. (p. 79).
}

Referindo-se ao mesmo aspecto, Duval (2014) justifica que isso ocorre porque a produção oral requer muito menos operações discursivas do que a produção escrita.

Sob essa perspectiva, conclui-se que os estudantes lapidaram suas deficiências e construíram o conceito de congruência de figuras ao longo das atividades que proporcionaram diferentes situações. Para Duval (2011), um conceito só é compreendido pelos estudantes quando eles conseguem transitar entre seus diferentes registros e reconhecê-los em mais de uma representação. Em concordância com o autor, para a construção do conceito de congruência, as diferentes atividades desta pesquisa abordaram o registro figural, discursivo (verbal e escrito), computacional, mental e algébrico. 
Verificou-se que o processo de construção do conceito de congruência de figuras ocorreu em etapas, gradativamente. As atividades da unidade 1 serviram de suporte e auxiliaram os estudantes na visualização da congruência de figuras durante todas as atividades subsequentes. Desse modo, a utilização de material manipulável como suporte para a sobreposição das figuras foi essencial no desenrolar de todo o processo.

Os estudantes realizaram a maioria dos tratamentos corretamente, sendo as conversões o fator que mais dificultou o processo. É exatamente isso que aponta Duval (2014), o qual afirma que os fracassos ou bloqueios dos alunos, nos diferentes níveis de ensino, aumentam, consideravelmente, cada vez que uma mudança de registro é necessária ou que a mobilização simultânea de dois registros é requerida. O autor alerta que as dificuldades dos estudantes, geralmente, encontram-se nas conversões, pois esse tipo de transformação demanda a capacidade de transitar entre os diferentes registros e isso, muitas vezes, não ocorre.

Cabe salientar que a referida experiência contribuiu para a formação continuada da professora investigadora, oportunizou assumir a postura de mediadora entre as diferentes maneiras apresentadas pelos estudantes de se expressar e de conjecturar suas ideias. Além disso, enriqueceu a formação acadêmica dos estudantes, permitindo-lhes verificar a importância da utilização de materiais de apoio como instrumentos de consulta e não como guias a serem seguidos fidedignamente.

Este trabalho é uma forma de desencadear discussões sobre o tema e tentar, na medida do possível, motivar os profissionais da área para que os conteúdos básicos para a formação do estudante do ensino fundamental, médio e superior sejam revisitados. É preciso desenvolver a competência de interpretar o mundo, sendo a Matemática uma das ferramentas para isso.

Experiências advindas de estudos semelhantes, principalmente realizados por Duval (2014), apontam para a necessidade de serem desenvolvidas ações específicas para a transposição dos obstáculos dos estudantes, pois somente a exposição dos enunciados, na forma tradicional, não se mostra suficiente para a compreensão de teoremas e axiomas. 


\title{
REGISTERS OF SEMIOTIC REPRESENTATION AND DYNAMIC GEOMETRY FOR THE TEACHING OF CONGRUENCES OF FLAT GEOMETRICAL FIGURES
}

\begin{abstract}
This article is an excerpt of a research of a Mast Course conducted by the first author and guidance for the second. Had up to analyze how students of a discipline of Geometry I build the concept of congruence of plane geometric figures through semiotic representation registers and dynamic geometry. The methodology was qualitative in the form of a case study, in which data collection methods, it permit to analysis of the productions of the students. Four teaching units were develop that led to the construction of the concept of congruence and classic cases of congruence of triangles through different registers of representation. We conclude Students did not have difficulties in carrying out the treatments, because they could move within a single record. The difficulty resided in conversions between different records. The research results showed that the proposed activities enabled the construction and understanding of the concept of congruence of plane figures by means of semiotic representation registers and the GeoGebra software.
\end{abstract}

KEYWORDS: congruence of plane geometric figures, semiotic representation registers, dynamic geometry, didactics' units. 


\section{REFERÊNCIAS}

BARBOSA, J. L. M. Geometria euclidiana. Coleção do professor de Matemática. Rio de Janeiro: SBEM, 2006.

BIANCHINI, E. Matemática. Ensino Fundamental. 60 ao 9o ano. 7 ed. São Paulo: Moderna, 2011.

BORBA, M. C; PENTEADO, M. G. Informática e educação matemática. Coleção Tendências em Educação Matemática. Belo Horizonte: Autêntica, 2003. 3 ed., $100 \mathrm{p}$.

BRASIL. Integração das tecnologias na educação. Ministério da Educação. Brasília: Seed, 2005.

BRASIL. Parâmetros curriculares nacionais: Matemática. Ministério da Educação. Secretaria da Educação Fundamental. Brasília: MEC/SEF, 1998, 148 p.

DANTE, L. R. Tudo é matemática: ensino fundamental. São Paulo: Ática, 2005.

DUVAL, R.A Cognitive analysis of problems of comprehension in a learning of mathematics. Educational Studies in Mathematics, v. 61, 2006, p. 103-131.

Registros de representações semióticas e funcionamento cognitivo da compreensão em matemática. In: MACHADO, S. D. A. (org.). Aprendizagem em matemática: registros de representação semiótica. Campinas, SP: Papirus, 2003. p. 11-33.

Rupturas e omissões entre manipular, ver, dizer e escrever: história de uma sequência de atividades em geometria. In: BRANDT, C. F.; MORETTI, M. T. (org.). As contribuições da teoria das representações semióticas para o ensino e pesquisa na educação matemática. ljuí: Ed. Unijuí, 2014, 256 p.

Ver e ensinar a matemática de outra forma: entrar no modo matemático de pensar: os registros de representações semióticas. CAMPOS, T. M. M. (org.). 1 ed. São Paulo: PROEM, 2011.

FLORES, C. R. Registros de representação semiótica em matemática: história, epistemologia, aprendizagem. Bolema, Rio Claro, v. 19, n. 26, 2006, p. 77-102.

GEOGEBRA. Página disponível em: <http://www.geogebra.org/cms/pt_BR/>. Acesso em 26 set. 2015.

GIOVANNI, J. R.; CASTRUCCI, B.; GIOVANNI Jr. A conquista da matemática. Ensino Fundamental. 80 ano. São Paulo: FTD, 2011. 
LAPERRIÉRE, A. Os critérios de cientificidade dos métodos qualitativos. In: POUPART, Jean et al. A pesquisa qualitativa: enfoques epistemológicos e metodológicos. Petrópolis: Vozes, 2010.

LEIVAS, J. C. P. Habilidade de visualização com alunos da licenciatura em matemática em geometria espacial. Anais do V Seminário Internacional de Pesquisa em Educação Matemática. Petrópolis: Rio de Janeiro, 2012.

LEIVAS, J. C. P. Imaginação, intuição e visualização: a riqueza de possibilidades da abordagem geométrica no currículo de cursos de licenciatura de matemática. Tese (Doutorado em Educação, Universidade Federal do Paraná). Curitiba, 2009, 249 p.

LORENZATO, S. Por que não ensinar geometria? A Educação Matemática em Revista, SBEM, n.4, p.3-13. set./1995.

LÜDKE M.; ANDRE, M. E. D. A. Pesquisa em educação: abordagens qualitativas. 2 ed. Rio de Janeiro: E.P.U, 2013.

MARIN, G. B. O software Cabri 3D como ferramenta de auxílio ao ensino e visualização de seções planas no cubo para alunos do ensino médio. Dissertação (Mestrado Profissionalizante em Ensino de Física e de Matemática - UNIFRA), Santa Maria: Centro Universitário Franciscano, 2013.

PROJETO ARARIBÁ. História: ensino fundamental. São Paulo: Moderna, 2010.

PROJETO ARARIBÁ. Matemática: ensino fundamental. 2 ed. São Paulo: Moderna, 2007.

REZENDE, E. Q. F.; QUEIROZ, M. L. B. Geometria euclidiana plana e construções geométricas. Campinas: Editora da UNICAMP, 2000.

SCHLEMMER, E. A geração eh web e eu, o professor. E agora? In: GONÇALVES, R. A.; OLIVEIRA, J. S.; RIBAS, M. A. C. (Orgs.), A educação na sociedade dos meios virtuais. Santa Maria: Centro Universitário Franciscano, 2009.

Aprovado: 2017-10-09

DOI: 10.3895/rbect.v10n3.3999

Como citar:

LEIVAS, J. C. P.; Fogaça, L. S. Registros de representação semiótica e geometria dinâmica para o ensino de congruência de figuras geométricas planas. Revista Brasileira de Ensino de Ciência e Tecnologia, v. 10, n. 3, 2017. Disponível em: <https://revistas.utfpr.edu.br/rbect/article/view/3999>. Acesso em: xxx. Correspondência:

José Carlos Pinto Leivas - leivasjc@unifra.br

Direito autoral: Este artigo está licenciado sob os termos da Licença Creative Commons-Atribuição 4.0 Internacional.

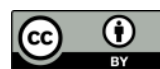

